\title{
Literatura, subjetividad política y educación. Una tríada para pensar*
}

Fecha de recepción: 8 de enero de 2018

Fecha de aprobación: 18 de abril de 2018

\section{Resumen}

La dimensión subjetiva de la lectura de literatura afecta a estudiantes y profesores, así como a lectores y escritores, la cual se configura de diferente modo, teniendo en cuenta la asimetría entre los actores. En este artículo, se revisa la relación entre la lectura de literatura y la subjetividad política en el ámbito educativo, entendiendo la importancia que se le otorga a la escuela y a la universidad, como escenarios de formación de ciudadanos. Se plantea que la literatura contribuye, de modo decisivo, a la configuración política de niños y jóvenes, lo cual supone darles herramientas para el ejercicio del poder y una acción pedagógica intencionada. En la revisión temática, se retomaron especialmente a Ruíz y Prada (2012), Nussbaum (1995, 1997, 2001, 2005, 2010) y Ricoeur (1996).

Palabras clave: subjetividad política; literatura; identidad narrativa; formación lectora.

\section{Emilce Moreno Mosquera}

Profesora de la Pontificia Universidad Javeriana. Magíster en Lingüística Universidad Nacional de Colombiana. moreno-e@javeriana.edu.co

*Artículo de reflexión

Citar: Moreno Mosquera, E. (enero-junio de 2018). Literatura, subjetividad política y educación. Una tríada para pensar. La Palabra,(32), 155-166. doi: https://doi. org/10.19053/01218530.n32.2018.8171. 


\title{
la palabra
}

\section{Literature, political subjectivity and education. A Triad for Reflection}

\begin{abstract}
Reading literature affects the subjective dimension of students and teachers, as well as readers and writers, and configures itself differently, taking into account the assymetry between agents. This article reviews the relation between the reading of literature and political subjectivity in the educational context, taking into account the importance given to the school and university as scenarios for the education of citizens. We propose that literature contributes decisively to the political configuration of children and young adults; this implies providing them with tools for the exercise of power and specifically oriented pedagogical action. The theorists discussed are Ruíz and Prada (2012), Nussbaum (1995, 1997, 2001, 2005, 2010) and Ricoeur (1996).
\end{abstract}

Key words: Political subjectivity; Literature; Narrative identity; Reading education.

\section{Littérature, subjectivité politique et éducation. Une triade pour réfléchir}

\section{Résumé}

La dimension subjective de la lecture de textes littéraires touche tant les élèves et les enseignants que les lecteurs et les écrivains. Cette dimension se construit de différentes formes, étant donné l'asymétrie entre les acteurs. Dans cet article nous examinerons la relation entre la lecture de textes littéraires et la subjectivité politique dans le domaine de l'éducation tout en mettant en évidence l'importance accordée à l'école et à l'université en tant que scénarios pour la formation des citoyens. Nous proposerons de quelle manière la littérature construit de forme decisive la configuration politique des enfants et des jeunes, en leur donnant des outils pour l' exercice du pouvoir et une action pédagogique intentionnée. Dans la révision thématique nous avons repris Ruíz y Prada (2012), Nussbaum (1995, 1997, 2001, 2005, 2010) et Ricoeur (1996)

Mots clés: subjectivité politique; littérature; identité narrative; éducation à la lectur 
Nuestra experiencia, sin la ficción, es demasiado limitada y estrecha. La literatura la extiende, nos hace reflexionar y pensar sobre cosas que de otro modo estarían demasiado distantes para sentirlas Martha Nussbaum.

\section{Introducción}

Leer literatura se constituye en una experiencia de conocimiento privilegiada, de reflexión ética sobre la condición humana y la sociedad. En ese sentido, se trata de "un ejercicio de conocimiento del mundo, de nosotros mismos y de otros" (Nunes, 1966, p. 193). A través de los cuentos, las novelas, la poesía y los diferentes géneros literarios, es posible la identificación y la conexión con las circunstancias de otros, otros espacios, otras voces que enriquecen la comprensión del mundo, la emoción e imaginación del sujeto. Precisamente, en este artículo me propongo argumentar en torno a la literatura como un campo de posibilidad de libertad para imaginar y de ser afectados y configurados en relación con los valores, los comportamientos, las acciones y en sí la experiencia humana ${ }^{1}$. Más allá de comprenderla como un divertimento o un instrumento para el goce ${ }^{2}$, le permite al lector profundizar en un ejercicio analítico sobre problemas $\mathrm{u}$ horizontes del ser y de lo social, a los que se abre la obra.

Esta tesis se plantea siguiendo a Prada (2010), Ruiz y Prada (2012), Nussbaum (1995, 1997, 2001, 2005, 2010), quienes explican la importancia de la literatura en la configuración de la subjetividad política de los ciudadanos, especialmente, en el escenario educativo. En el desarrollo de este artículo, se aborda lo referido a: subjetivación política, identidad narrativa y narración. En segundo lugar, están los argumentos que derivan de la obra de Nussbaum y de otros autores como Vargas Llosa, Ricoeur, Prada, y Ruíz y Prada. Finalmente, se concluye la reflexión haciendo referencia a la importancia de la formación lectora en ámbitos privilegiados como la escuela y la universidad.

\section{Relaciones entre subjetiva- ción política, identidad narra- tiva y educación}

La categoría subjetividad política se relaciona con las diferen- tes percepciones, expectativas, deseos que dirigen las prácticas sociales de los sujetos. De acuerdo con ello, se requiere de autoconocimiento y reflexividad para poder intervenir como agentes sociales y políticos. En investigaciones como las de Carretero y Kriger (2010), Ruiz y Carretero (2010) y Kriger (2010), se plantea que a través del desarrollo de la comprensión histórica se puede aportar reflexividad y conciencia para intervenir en el mundo. Esto es, la subjetividad política y la comprensión histórica posibilitarían la interpretación de la herencia histórica y el asentimiento o disentimiento con los significados de la realidad, lo cual supone que los sujetos estén de acuerdo o en desacuerdo con los proyectos sociales y se impliquen en la construcción y transformación del contexto del que forman parte. Al respecto, Kriger (citada en Ruíz y Prada, 2012) explica sobre el sujeto político lo siguiente:

llamo sujetos políticos a los agentes sociales que poseen conciencia de su densidad

Algunas investigaciones que apuntan a pedagogías para la construcción de sujetos, como: Saavedra Rey (2017); González Otero (2017); Higuera Guarín (2016). Pinzón (2014), Brijaldo (2014), Ávila (2014), Vargas (2014) hacen énfasis en la escritura literaria desde el cuerpo como una práctica que (re)construye los sujetos. Por otro lado, López (2016), Sierra Díaz (2016), Ortiz Caraballo (2016) y González Otero (2016) trazan caminos en la lectura crítica que apoyan esta reflexión y reconfiguración subjetiva a través de miradas al género o etnicidad.

2 Este tipo de perspectiva, en que la literatura es usada en el aula con un énfasis en la compresión del lenguaje literario y estimulación del placer del texto, puede verse desarrollada en investigaciones como: García-Dussan (2016), Altamirano (2016) y Bolívar y Gordo (2016). 
histórica y se autocalifican como tomadores de decisiones a futuro, y responsables de la dimensión política de sus acciones, aunque no puedan calcular ni controlar todas las consecuencias, resonancias o alcances de las mismas (p. 47).

Así mismo, la subjetividad política se concibe de modo narrativo, siguiendo a Ruiz y Prada (2012), “en la construcción de relatos sobre sí mismo -en tanto individuo y como miembro de colectivos humanos que eventualmente poseen intereses compartidos- y en el significado que el sujeto les otorga a las prácticas sociales y políticas" (p. 51). Estos autores explican la subjetividad política como reto de transformación, para lo cual se hacen necesarios cinco elementos: la identidad, la narración, la memoria, el posicionamiento y la proyección. En este ensayo, se retoma especialmente lo referido a narración e identidad narrativa, por ser categorías fundamentales para pensar los procesos de subjetivación, los cuales están efectivamente atravesados por el lenguaje y posibilitan las diferentes formas de agenciar las obras literarias. Al respecto, estos autores plantean que a partir de la construcción de relatos o narraciones tejidas sobre la vida individual o colectiva "configuramos una trama para desplegar una manera de ser propia, y evaluamos retrospectiva y proyectivamente el curso de nuestra vida [las iniciativas, los planes de vida, las acciones emprendidas, las promesas]" (Ruíz y Prada, 2012, p. 49), lo cual se constituye en identidad narrativa.

Se parte del supuesto de que el conocimiento narrativo, las narraciones, los relatos no se limitan a representar la realidad, sino que la construyen en los modos en que los seres humanos dan sentido a sus vidas y al mundo. De acuerdo con ello, predomina la idea de que la acción humana es un proceso relacional, que supone el cruce y el intercambio de las narraciones personales de cada sujeto que interactúa con otros, $y$, en esa relación, crea y da sentido a su vida. Esto iría en la dirección de lo planteado por Bolívar (2002) quien da "prioridad a un yo dialógico (naturaleza relacional y comunitaria de la persona), donde la subjetividad es una construcción social, interactiva y socialmente conformada en el discurso" (p. 4). En términos de Ruíz y Prada (2012), se concibe la narración como un acto intersubjetivo, "se narra para alguien, se apren- de a narrar de alguien" (p. 50). En ese sentido, la subjetividad política es "una dimensión de ese ser humano que somos y que vamos siendo con otros" (Ruíz y Prada, 2012, p. 35). En esta dinámica, el lenguaje cumple un papel fundamental en la construcción de significados y experiencias, dado que estos se encuentran mediados semiótica y lingüísticamente. Además, los sujetos otorgan significado a las narraciones dependiendo de su experiencia y de su historia.

Paul Ricouer (1996) estudia la identidad narrativa en clave de la búsqueda de lo temporal y la forma en que las narraciones generan tramas como "síntesis de lo heterogéneo"3, de modo que el lector puede hacer una narración de su vida misma. Sin embargo, esta identidad no se expresa en una primera persona singular, sino en un acto intersubjetivo, que encuentra en la narración, en los textos literarios y poéticos un modo de entender fenómenos o problemas del sujeto en tanto individuo o miembro de un grupo social. Es precisamente, ese poder de la literatura de hacer referencia a lo humano y de vincular la emoción, la imaginación, la belleza del lenguaje, lo poético, para adquirir un conocimiento de sí

3 De acuerdo con Prada (2010), Ricoeur plantea que en la narración se imitan o se reproducen acciones de los hombres, en un proceso dinámico que acentúa la «imaginación creadora». En la construcción y producción de la narración, se plantean tres fases: mímesis I, la prefiguración; mímesis II, la configuración; y mimesis III, la refiguración (Ricoeur, 2004). Específicamente, "la síntesis de lo heterogéneo" se relaciona con la mímesis II, esto es, el proceso de configuración poética, a partir de la selección de los eventos que tienen significado para el relato. 
y de los otros, el que interesa en este artículo.

La lectura de textos literarios como un arte de creación, de vivir mundos posibles y de producir en los lectores confrontaciones, reflexiones, búsquedas, preguntas, desde lo humano, lo social, lo histórico, lo crítico; se constituye en una posibilidad de educar para la vida y para asumirse en un mundo en constante devenir, diverso cultural e ideológicamente, sediento de actitudes democráticas y reflexivas en los diferentes espacios de la vida. La educación desde este lugar, no se entiende como una imposición de formas, "ha de concebirse como la construcción del encuentro y del diálogo para la comprensión de los sentidos posibles del ser humano y de sus mundos, buscando contribuir a que puedan ir aflorando las múltiples e insospechadas formas de lo humano" (Campo y Restrepo, 1999, p. 12).

La educación en los diferentes niveles, podría desarrollar la conciencia sobre la importancia de la literatura como una forma potente de conocimiento que posibilita horizontes de pensamiento, experiencias, sensibilidades y una actitud de apertura para comprender acerca de la condición humana. Sin embargo, en ese proceso formativo, desempeñan un papel importante los lectores quienes se acercan con ciertos propósitos e hipótesis, guiadas a partir del residuo de su experiencia. La literatura dialoga y entra en relación con infinitud de campos del conocimiento - de ahí su carácter polisémico- $\mathrm{y}$ en estas relaciones seguramente están las que el lector puede establecer.

Igualmente, resulta fundamental el rol de los educadores como mediadores en el acceso a las obras literarias. Solo espíritus apasionados por la literatura pueden seducir, sacar chispas al lenguaje y contagiar de entusiasmo a los lectores con historias que abren sentidos en torno a la actividad cultural, histórica y estética del hombre. Se trata de posibiliar experiencias de enseñanza en las cuales se aporten herramientas para entender la obra, su propuesta de escritura, el diálogo que establece con otras obras, los usos del lenguaje, la función poética del lenguaje, y todo un arsenal que le permita acceder a la obra, disfrutándola, pero también interpelándola y búscando entender fenómenos o problemas mayores (humanos, sociales, políticos, históricos, culturales, etc.). Pero, más allá está la posibilidad de la literatura de abrir caminos de diálogo con la obra y de configurar subjetividades, en este artículo en particular: subjetividades políticas, es decir, prácticas y discursos orientados al reconocimiento de sí y del otro, de la pluralidad (ideológica y cultural), de la necesidad de generar espacios de argumentación que redunden en el descentramiento y aceptación de la diversidad, la implicación de los sujetos en la construcción y transformación de su contexto, en un vínculo entre la condición de lo humano, la vida y la literatura.

De acuerdo con lo explicado anteriormente, la identidad narrativa, la subjetividad política y la lectura de textos literarios, se relacionan desde un punto de vista estético y ético, en tanto que la literatura puede modificar o afectar al lector. En lo relativo a la experiencia estética de la lectura, Prada (2010) plantea que no se puede explicar sin el goce, "no entendido únicamente como la satisfacción de los prejuicios, o como resultado de una lectura que conmueve o hace sufrir" (p. 90). Existe una relación íntima entre el goce y la catharsis, es decir, "el efecto más moral que estético de la obra: se proponen, mediante la obra, valoraciones nuevas, normas inéditas, que atacan o socavan las 'costumbres' corrientes" (Ricoeur citado en Prada, 2010, p. 91). Y la catharsis tiene un efecto moral, puesto que "ante todo, exhibe un poder de clarificación, de examen, de instrucción ejercida por la obra merced al distanciamiento respecto a nuestros propios afectos" (Ricoeur citado en Prada, 2010, p. 91). En esa medida, hay una vinculación entre la estética y la ética. 
En lo concerniente a la experiencia ética de la lectura, desde el mismo Ricoeur (1990), se plantea la lectura como una experiencia de pensamiento $\mathrm{y}$ de conocimiento entre el autor, el lector y la acción, sometida a las variaciones de la imaginación. Esa dimensión ética tendría que ver con el vínculo que podrían establecer los sujetos con los textos literarios, al reconocer en ellos lugares comunes sobre la condición humana ${ }^{4}$.

\section{Importancia de la imagina- ción literaria}

Se ha argumentado en torno a la capacidad del arte narrativo de generar posibilidades de reconocimiento, sensibilidad, visibilización, comprensión y posicionamiento frente "al otro", como lo explica Nussbaum (2001), la literatura nos permite ver las vidas de quienes son diferentes a nosotros "con un interés mayor al de un turista casual; con un compromiso y entendimiento receptivos, y con ira ante la forma en que nuestra sociedad rehúsa a algunos la visibilidad" (p. 125). Pero, ¿en qué contribuye la literatura a la formación de subjetividad política de los sujetos? De acuerdo con Nussbaum (1997),

Las obras literarias que promueven la identificación y la reacción emocional de- rriban esas estratagemas de autoprotección, nos obligan a ver de cerca muchas cosas que pueden ser dolorosas de enfrentar, y vuelven digerible este proceso al brindarnos placer en el acto mismo del enfrentamiento (p. 30).

Precisamente, un género como la novela, que tiene gran popularidad, podría "servir de eje de la reflexión moral" (Nussbaum, 1997, p. 31). Para ilustrar esto, la autora en su obra Justicia poética, en donde se analiza la novela Tiempos dificiles de Charles Dickens, en la cual a través del personaje del señor Gradgrind se muestra una visión normativa de una economía politica cientifica y otra de imaginación política científica. La primera apunta a una mentalidad económica utilitarista de productividad, en una lógica capitalista. La segunda muestra las acciones humanas, las desgracias, el modo en que la felicidad y el dolor afectan a los personajes, sus pasiones, sus luchas, sus temores, y en sí todo lo que configura la naturaleza humana, mostrada a través de los personajes. Esto último es, precisamente, sobre lo que podría reflexionarse, sobre lo que podría haber identificación y reacción emocional. Al respecto, pensando en el caso de la novela retomada por Nussbaum (1997), explica que: induce al lector a interesarse por los personajes, a participar de sus proyectos, temores y esperanzas, a compartir sus intentos de desentrañar los misterios y perplejidades de sus vidas. La participación del lector se explicita en muchos puntos de la narración. $Y$ los lectores comprenden que en cierto modo se trata de su propia historia, pues muestra posibilidades de elección que en cierto sentido también son las suyas, aunque las circunstancias concretas varíen (pp. 59-60).

En el Cultivo de la humanidad, Nussbaum retoma la tragedia el Filoctetes de Sófocles, en el cual Filoctetes es menospreciado por Odiseo. Este se constituye en un personaje que evidencia la tragedia del dolor-físico, psíquico y moral-. Filoctetes había sido un famoso arquero de Tesalia, que fue mordido por una serpiente, mientras limpiaba el altar de la ninfa Crisa (vv. 194, 270, 1327). Una vez se le infectó gravemente la herida "enfermo de salvaje enfermedad", como le dice el reflexivo coro de la tragedia, Odiseo convenció a los demás caudillos griegos de abandonarlo en la isla de Lemnos, en la cual permaneció por diez años. Había sido, entonces, excluido del mundo heroico. Además, condenado a la muerte social, pues era un hombre "sin amigos, sin socorro, sin patria, muerto en-

$4 \quad$ Para ampliar acerca de la inclinación ética de la literatura pueden revisarse investigaciones como: Higuera (2016) y Cárdenas (2002). 
tre los vivos" [ä́ı

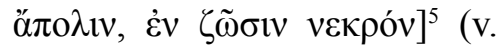
1018). Incluso, condenado a vivir sin comunicarse, sin usar su lenguaje, como se lo hace saber a Neoptólemo "la voz es lo que deseo oír" [ $\varphi \omega v \tilde{\eta} s \delta$ '

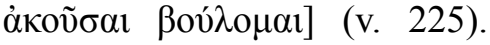
No obstante, contaba con el imbatible arco de Heracles, con el que cazaba torcaces y era un arma preciada y deseada por Neoptólemo y Odiseo, personajes que a través de sus argucias, logran mostrar al espectador el lado más humano de Filoctetes. André Gide (citado en Wilson, 2009) explicó que, gracias a su abstinencia lingüística, el héroe griego se habría convertido en un solitario avant la lettre, que se descubre a sí mismo, a través del silencio y el significado de las palabras:

Aprendí a expresarme mejor ahora que ya no estoy entre los hombres. Entre cazar y dormir, me ocupo de pensar. Mis ideas, desde que estoy solo y nada las perturba, ni siquiera el sufrimiento, han tomado un ritmo sutil que a veces puedo seguir a duras penas. Llegué a conocer más sobre los secretos de la vida de lo que mis maestros nunca me revelaran. Y me acostumbré a contar la idea de mis sufrimientos, y si la frase era realmente bella, bastaba para consolarme; a veces llegaba hasta a olvidarme de mi tristeza al pronunciarla. Acabé por comprender que, inevitablemente, las palabras se vuelven más bellas cuando dejan de estar articuladas en respuesta a las demandas de otros (p. 207).

La lectura de esta obra exigiría, por ejemplo, la capacidad de estar en el lugar de la otra persona -empatía- y preguntarse por "si la persona ha sopesado con su propio juicio todas las consecuencias de lo ocurrido" (Nussbaum, 2001, p. 128). En el caso de Filoctetes, Sófocles "desafió a su público a que vieran sin acobardarse lo que para los personajes resultaba desagradable y repugnante: el pus, gritos blasfemos o el cuerpo de Filoctetes cubierto de úlceras" (Nussbaum, 2001, p. 137). La tragedia tiene esa posibilidad de involucrar al espectador en lo más profundo de su ser, es decir, exponerlo a la desgracia, al sufrimiento, aunque los lectores-espectadores estén distantes en el espacio y en el tiempo.

De acuerdo con lo anterior, en el proceso de lectura se generan juicios de censura o aprobación de las acciones de los personajes de la trama ${ }^{6}$. De ahí que resulte comprensible el hecho de que en la historia de la literatura se hayan establecido ciertos arquetipos de personajes virtuosos (Polixena, Héctor, Antígona) $u$ otros que se alejan de la virtud y caen en excesos (Hécuba, Creonte, Otelo, Lady Macbeth). El lector, entonces, explicita sus prejuicios y concepciones, establece un marco desde el cual interpreta el mundo y toma distancia o se pone en el lugar de estos personajes y comprende así el universo cultural en que se insertan sus vidas, dando lugar al proceso de refiguración de sí:

la refiguración mediante el relato pone de manifiesto un aspecto del conocimiento de sí que supera con mucho el marco del relato. A saber: que el sí mismo no se conoce de un modo inmediato, sino indirectamente, mediante el rodeo de toda clase de signos culturales, que nos llevan a defender que la acción se encuentra simbólicamente mediatizada (Ricoeur, 1999, p. 227).

La apropiación a través de la identificación con un personaje, implica un ejercicio de sometimiento a las variaciones imaginativas, que se convierten en ese sentido en variaciones

\footnotetext{
$5 \quad$ Textos en griego tomados de CD PHI 7 (Packard Humanities Institute).

6 Al respecto, Ricoeur (1999) explica lo siguiente: "Ya señalaba Aristóteles que los personajes son o bien «mejores» que nosotros, como en la tragedia, o «peores» e iguales, como en la comedia. En cualquier caso, su fortuna o su desgracia nos parecen merecidas o inmerecidas. Incluso en la novela moderna, en la que la calificación moral de los personajes es tremendamente ambigua, no podemos dejar de querer el bien de aquellos que estimamos. Resulta comprensible por qué sucede de ese modo: la intelección narrativa se asemeja al juicio moral, en la medida en que explora los caminos mediante los que la virtud y el vicio conducen o no a la felicidad y a la desgracia" (p. 226).
} 
del sí mismo. Este se evidencia en la célebre frase de Rimbaud «yo es otro» (Ricoeur, 1999, p. 228). Dicho ejercicio posibilitaría una mejor comprensión de sí, "se trata de una identidad narrativa, en tanto que sólo acontece en su interpretación" (Aranzueque y Gailondo, 1999, p. 24). Sobre ello, Vargas Llosa (2000) aduce lo siguiente:

La literatura no dice nada a los seres humanos satisfechos con su suerte, a quienes colma la vida tal como la viven. Ella es alimento de espíritus indóciles y propagadora de inconformidad, un refugio para aquel al que sobra o falta algo, en la vida, para no ser infeliz, para no sentirse incompleto, sin realizar en sus aspiraciones. Salir a cabalgar junto al escuálido Rocinante y su desbaratado jinete por los descampados de La Mancha, recorrer los mares en pos de la ballena blanca con el capitán Ahab, tragarnos el arsénico con Emma Bovary o convertirnos en un insecto con Gregorio Samsa, es una manera astuta que hemos inventado a fin de desagraviarnos a nosotros mismos de las ofensas e imposiciones de esa vida injusta que nos obliga a ser siempre los mismos, cuando quisiéramos ser muchos, tantos como requerirían para aplacárselos incandescentes deseos de que estamos poseídos (p. 41).

En el desarrollo de una sensibilidad inconforme, como lo sugiere Vargas Llosa, el lector cumple un papel fundamental en la interpretación, a fin de llegar al ethos de lo que ha sustraído de la lectura literaria. Es decir, el lector interpreta vinculando sus emociones, sus sentidos, su sensibilidad, su deseo, su experiencia, su subjetividad, pero en su proceso formativo aprende a habitar las obras de un modo reflexivo, analítico y guiado por ethos personal. Es decir, una disposición para formular y resolver un problema del ser o de la sociedad ligado a la obra, una suerte de actitud y disposición del lector que interpela lo que lee desde algún lugar.

La literatura imbricada a la vida en escenarios educativos, exige de una participación comprometida de los lectores, los profesores conectados a espacios de construcción de subjetividad política, como es el caso de la escuela, la universidad y las bibliotecas públicas. Si bien la li- teratura podría modificar la subjetividad política y la relación con el mundo por parte de los sujetos, por sí sola "no transforma la sociedad" (Nussbaum, 2001, p. 132). En ese sentido, se constituye en una posibilidad de reflexionar sobre la condición y la acción humana, pero, por ejemplo, en la obra de Nussbaum habrá que entenderla conectada a otros aspectos ligados al cultivo de las humanidades ${ }^{7}$. Esta autora promueve la idea sobre la necesidad de formar estudiantes verdaderamente socráticos, es decir, que lean con espíritu crítico, que se formulen preguntas a medida que avanzan en sus textos, que estén en constante búsqueda, que interpelen, que abran horizontes de lectura ligados a problemas de orden social, político y cultural. Es decir, una actitud de examen de la vida que tiene origen "en la antigua tradición griega de los festivales de tragedia, en donde asistir a una obra estaba estrechamente vinculado con la discusión y deliberación sobre valores cívicos fundamentales" (Nussbaum, 2001, p. 139). Se requiere, entonces, de una formación literaria que revele su potencial como fuerza educativa y liberadora.

\footnotetext{
La obra de Nussbaum en torno a la defensa de las humanidades, en especial, a la literatura [ligada a la filosofía] y a las artes como vehículos para la humanización y desespecialización, por ejemplo, de abogados y de economistas es relevante. Así como, la elaboración de una compleja teoría acerca de las emociones, desarrollada en obras como: Justicia poética, El conocimiento del amor, El cultivo de la humanidad. Una defensa clásica de la reforma en la educación liberal, Sin fines de lucro. Por qué la democracia necesita de las humanidades. Precisamente, sobre ello, en un apartado del discurso de recepción del Premio Príncipe de Asturias (2012), la autora plantea lo siguiente: las Humanidades nos proporcionan no sólo conocimientos sobre nosotros mismos y sobre los demás, sino que nos hacen reflexionar sobre la vulnerabilidad humana y la aspiración de todo individuo a la justicia, y nos evitarían utilizar pasivamente un concepto técnico, no relacionado con la persona, para definir cuáles son los objetivos de una determinada sociedad. No me parece demasiado atrevido afirmar que el florecimiento humano requiere el florecimiento de las disciplinas de Humanidades.
} 


\section{A modo de epílogo}

Se ha tratado de mostrar la lectura de textos literarios como una experiencia intensa, que configura la subjetividad de los lectores. Cuando se lee literatura, se está en una búsqueda e indagación sobre la realidad representada, lo cual implica poner en crisis las creencias previas. A través de la literatura, se puede tejer una imagen de los diferentes lenguajes que circulan socialmente, de los saberes, de los valores y los pensamientos colectivos que, en determinado momento histórico, se constituyen en la realidad de un contexto social. De ahí la importancia de diversificar y ampliar los espacios donde se propenda por reconocer y participar de los dones de la literatura. Precisamente, la escuela y la universidad se constituyen en lugares privilegiados para ello. El diálogo y la discusión en torno a los tópicos y motivos literarios, los personajes, las circunstancias de la vida y la condición humana, que se abordan en textos literarios se constituyen en una fuente inagotable de la pedagogía de la literatura. El significado ético de la literatura, aludido anteriormente, exige elegir modos de leer que afecten realmente al lector, la comprensión de motivos literarios como un acercamiento al mundo de la vida y una oportunidad para pensarse sobre sí mismo y en relación con otros. Esto se plantea siguiendo a Larrosa (1998):

[...] la experiencia de lectura es intransitiva: no es el camino hacia un objetivo previsto, ante una meta que se conoce de antemano, sino que es una apertura hacia lo desconocido, hacia lo que no es posible anticipar y prever. [...] La pedagogía (quizá toda pedagogía) ha intentado siempre controlar la experiencia de la lectura, someterla a una causalidad técnica, reducir el espacio en el que podría producirse como acontecimiento, capturarla en un concepto que imposibilite lo que podría tener de pluralidad, prevenir lo que tiene de incierto, conducirla hacia un fin preestablecido. Es decir, convertirla en experimento, en una parte definida y secuencia de un método o de un camino seguro y asegurado hacia un modelo prescriptivo de formación (pp. 29-30).

En concordancia con lo planteado por Larrosa, se requiere un proceso formativo que aporte a la resignificación de las obras literarias; más allá del goce, se exhorta por una visión crítica y conectada problemas humanos de mayor alcance, una experiencia de lectura que requiere del "continuo escrutinio crítico del pensamiento moral y político, de nuestras intuiciones morales y políticas, y del juicio de otros" (Nussbaum, 1997, p. 112).

Ese modo de leer es de capital importancia tanto para la formación de la curiosidad intelectual y emocional de los niños y de los jóvenes, como para el reconocimiento de la dimensión ética de la literatura, de modo que posibilite el reconocimiento de la otredad y se conjure la amenaza del totalitarismo. Se trata de abrir una puerta a extraños huéspedes y mundos posibles, los cuales algunos descansan por un tiempo en la conciencia, mientras otros permanecen para siempre en la memoria. 


\section{la palabra}

\section{Referencias}

Altamirano, F. (2016). Didáctica de la literatura: ¿cómo se contagia la literatura? La Palabra, (28), $155-$ 171.

Aranzueque, G., \& Gabilondo, A. (1999). Introducción. En Historia y narratividad (pp. 9-39). México: Paidós.

Ávila, A. (2014). De la germinación de lo siniestro: La belleza en espejo roto. La Palabra, (24), 99-109.

Bolívar, A. (2002). “De nobis ipsis silemus?”: Epistemología de la investigación biográfico-narrativa en educación. Revista Electrónica de Investigación Educativa, 4(1). Recuperado de http://redie.uabc. uabc.mx/vol4nol/contenido-bolivar.html

Bolívar, C., \& Gordo, A. (2016). Leer texto literario en la escuela: una experiencia placentera para encontrarse consigo mismo. La Palabra, (29), 199-211.

Brijaldo, G. (2014). Interpretaciones íntimas sobre la escritura performativa. La Palabra, (24), 111-117.

Campo, R., \& Restrepo, M. (1999). Formación Integral. Modalidad de educación posibilitadora de lo humano. Bogotá: Formas en Educación, Pontificia Universidad Javeriana.

Cárdenas, J. A. (2002). Pedagogía y vocación ética de la literatura. Revista Educación y Pedagogía, 14(32), 121-133. Recuperado de http://aprendeenlinea.udea.edu.co/revistas/index.php/revistaeyp/article/view/6738

Carretero, M., \& Kriger, M. (2010). Enseñanza de la historia e identidad nacional a través de las efemérides escolares. En M. Carretero \& J. A. Castorina, La construcción del conocimiento histórico. Enseñanza, narración e identidades (pp. 57-80). Buenos Aires: Paidós.

CD PHI 7 (Packard Humanities Institute)

García-Dussán, É. (2016). Sobre el misterio estético en el texto literario: claves para una pedagogía de la literatura. La Palabra, (28), 141-154.

González-Otero, A. (2016). Definiciones y aproximaciones teóricas al género de la literatura de viajes. La Palabra, (29), 65-78.

González-Otero, A. (2017). El diario: La escritura autobiográfica en su dimensión sociocultural y sus posibilidades cognoscitivas y creativas. La Palabra, (30), 151-167.

Higuera, G. (2016). De la estética de la recepción a la animación a la lectura: consideraciones teóricas para una propuesta de animación de la lectura literaria en espacios no convencionales. La Palabra, (28), 187-199. 
Kriger, M. (2010). Jóvenes de escarapelas tomar: escolaridad, comprensión histórica y formación política en la Argentina contemporánea. La Plata: UNLP.

Larrosa, J. (1998). La experiencia de la lectura. Estudios sobre Literatura y Formación. Barcelona: Editorial Laertes.

López, H. (2016). Pedagogía, feminismo y emociones: una lectura de "Lección de cocina" de Rosario Castellanos. La Palabra, (29), 79-88.

Nunes, B. (1996). Ética e Leitura. En Leitura: Teoria e Prática. Campinas: ALB.

Nussbaum, M. (1995). Forma y contenido, filosofía y literatura. Estudios de Filosofía, (11), 43-105.

Nussbaum, M. (1997). Justicia poética. La imaginación literaria y la vida pública. Barcelona: Andrés Bello.

Nussbaum, M. (2001). El cultivo de la humanidad. Santiago de Chile: Editorial Andrés Bello.

Nussbaum, M. (2005). El conocimiento del amor. Ensayos sobre filosofia y literatura. Madrid: Machado Libros.

Nussbaum, M. (2010). Sin fines de lucro. Madrid: Katz Editores.

Ortiz-Caraballo, C. (2016). Los Cuícatl de Acomiztli Netzahualcóyotl: entre el ritual y la estética del pueblo Nahual. La Palabra, (29), 45-63.

Pinzón-Manrique, H. (2014). La literatura como in-corporación: el cuerpo como proceso. La Palabra, (24), 91-97. doi: https://doi.org/10.19053/01218530.2504

Prada, M. (2010). Lectura y subjetividad. Una mirada desde la hermenéutica de Paul Ricoeur. Bogotá: Uniediciones.

Ricoeur, P. (1996). Sí mismo como otro. Madrid: Siglo XXI editores.

Ricoeur, P. (1999). Historia y narratividad. México: Paidós.

Ricoeur, P. (2004). Tiempo y narración I. México: Siglo XXI editores.

Ruiz-Silva, A., \& Prada, M. (2012). La formación de la subjetividad política. Propuestas y recursos para el aula. Buenos Aires: Paidós.

Ruiz-Silva, A. y Carretero M. (2010). Ética, narración y aprendizaje de la historia nacional. En M. Carretero \& J. A. Castorina, La construcción del conocimiento histórico. Enseñanza, narración e identidades. Buenos Aires: Paidós. 
Saavedra, S. (2017). Formación (Bildung) y creación literaria. "Llegar a ser lo que se es" en diversos mundos posibles. La Palabra, (31). doi: https://doi.org/10.19053/01218530.n31.2017.7267

Sierra-Díaz, D. (2016). El Muntu: la diáspora del pensamiento filosófico africano en Changó, el gran putas de Manuel Zapata Olivella. La Palabra, (29), 23-44. doi: https://doi.org/10.19053/01218530. n29.2016.5699

Vargas Llosa, M. (2000). Un mundo sin novelas. Letras Libres, (22), 38-44.

Vargas Quiroz, A. (2014). Me gustan tus ojos miopes (o del diálogo con Hélène Cixous para llevar al cuerpo, a la literatura, a la vida). La Palabra, (25), 143-156. doi: https://doi.org/10.19053/01218530.2877

Wilson, R. (2009). Filoctetes: a ferida e o arco. En Sófocles, Filoctetes (pp. 193-213). São Paulo: Editora 34 . 